\title{
Widening Participation: Developing 'Academic' Programmes in Light of Recruitment Pressure
}

\author{
Matthew Johnson, Lecturer in Politics, Lancaster University \\ Rosie Mutton, PhD Student, Lancaster University \\ Email: m.johnson@lancs.ac.uk
}

\begin{abstract}
The emergence of the 'Widening Participation' (WP) agenda in English Higher Education (HE) has been intensified by the shift to tuition fees of $£ 9000$ or more. Now, universities have an obligation to devote funds to encouraging participation of students from a range of groups identified by the Office for Fair Access as being under-represented and disadvantaged. For a discipline like Politics/International Relations, with implicit concerns for the examination of concepts such as social justice, there is both prima facie reason and intellectual capacity for engagement in WP programmes. In this article, we explore the tension between 'intrinsic' 'professional' WP and 'instrumental' 'academic' WP, arguing that a number of pressures need to be navigated in order for academics to engage successfully in such work. We advance an approach to maximising the value of WP programmes for academics by way of illustrating the considerations, costs and benefits of engaging with the agenda. While the article draws on experience in England, the implications are relevant to the profession in most industrialised countries, since growing inequality and the rising cost of HE study mean that WP is an agenda which will only expand.
\end{abstract}

Key words Widening participation; outreach; recruitment; Politics; North East of England

\section{Introduction}

The gradual emergence of the 'Widening Participation' (WP) agenda in Higher Education (HE) in England (see Tight, 2012) has been intensified by the shift to to tuition fees of $£ 9,000$ or more (Jones and Lau, 2010; OFFA, 2016a). Now, universities charging higher fees have an obligation to devote funds to facilitating the participation of students from a range of eleven groups identified by the Office for Fair Access (OFFA) (2016b), the independent regulator of fair access to $\mathrm{HE}$ in England, as being underrepresented and disadvantaged. These include those with low incomes, those with disabilities and those from certain ethno-cultural groups. These criteria are often overlapping and intertwined, such that students who fulfil one 
criterion, may often fulfil others, compounding disadvantage in unique ways (see Rainford, 2016; Thomas, 2001). This disparate set of criteria presents universities with a range of serious challenges in terms of developing targeted and appropriate strategies to appeal to particular students. For a discipline like Politics/International Relations (IR), with implicit concerns for the examination of concepts such as social justice, there is both prima facie reason and intellectual capacity for engagement in WP programmes (see broader discussion in Greenbank, 2006a). As a Politics/IR subject area at Lancaster University, we have found that our existing commitment to diversity has fed gradually into the WP agenda emerging in other pre-1992 institutions (Graham, 2013; Boliver, 2015). This, combined with a temporary fall in UCAS application numbers in 2014, led us to develop an integrated programme of outreach, WP and recruitment focused on a region - the North East of England (NE) - which is seriously disadvantaged in terms of access to HE (see Department for Business, Innovation and Skills, 2014: 19-20). Conceptually, we understand outreach to denote endeavours of knowledge exchange that take academics, their knowledge and the products of their labour beyond academia and into non-academic communities; WP to denote the practice of broadening access to $\mathrm{HE}$, and recruitment to denote the process of attracting students to study at particular institutions or particular courses. We chose the NE as the focus of our efforts by virtue of this article's primary author's background and connections there, as well as the relative deprivation of individuals within the region. In pursuing our integrated programme, which has contributed to reversing our under-recruitment into significant overrecruitment over the past two years, we have encountered a number of issues which academics participating in such activities may need to consider in order to make best use of their efforts.

In what follows, we outline points of tension within universities between 'intrinsic' and 'instrumental' approaches to WP, which create parameters for action and complication in present approaches, before advancing one approach to maximise the value of WP programmes for academics. We highlight the need of programmes to pursue regional foci and to integrate outreach, WP and recruitment agendas into a single programme. We then reflect on a number of important lessons from the programme's development, highlighting potential complications which can derail plans. While the article draws on experience in England and is intended to be of most practical relevance to academics working within that $\mathrm{HE}$ context, the implications are relevant to the profession in most industrialised countries, since growing inequality and the rising cost of HE study mean that WP is an agenda which 
will only expand. Given that practical application, we do not seek to trace the history of WP policy development. Comprehensive critical examinations of that history can be found in Brown (2012), Thomas (2001), Lewis (2002) and Greenbank (2006b and 2006c), which demonstrates a lack of consultation with those affected by WP policy and a tendency to make overarching assumptions about the uniformity of 'disadvantage' as a whole. We discuss our experience of the consequences of the development of policy on academics and make suggestions with regard to how policy may minimise some of the harms it presently inflicts. We accept, fundamentally, that the participants in such endeavours, particularly those in schools, face hostile conditions attendant to austerity that impose constraints on their ability to coordinate and co-operate efficiently. As such, any expression of concern over the predictability of schools below ought to be read sympathetically as a complicating factor to accommodate, rather than critically as a reason not to try. To begin, it is necessary to clarify the methods of the article.

\section{A note on method}

The research underpinning this work is grounded in a practical action method deployed within the department, in accordance with Denscombe's account (2010: 6), to understand and 'solve a practical problem' and 'produce guidelines for best practice'. The 'best practice' in this instance will necessarily differ from institution to institution, but the questions which departments ought to ask themselves are broadly similar. The answers to those questions will necessarily differ over time, and the answers we offer below as means of illustration will be evaluated annually as part of the 'feedback loop in which initial findings generate possibilities for change which are then implemented and evaluated as a prelude to further investigation' (Denscombe, 2010: 126). Although Denscombe (2010: 135) is surely correct to state that this necessarily inhibits impartiality, it is selfdefeating to disrupt or misrepresent the findings. In keeping with Susman and Evered's (1978 : 589) claim that action research is more of a strategy than a specific method, this article draws on a range of qualitative and quantitative means of acquiring data. Most importantly, the research was conducted by us, the authors of this article, as academic practitioners, on our own practice as we were engaged in it (Edwards and Talbot, 1994: 52; Maclean and Mohr, 1999: ix).

The article constitutes a case study, which Yin (1984: 23) has defined 'as an empirical inquiry that investigates a contemporary phenomenon within its 
real-life context; when the boundaries between phenomenon and context are not clearly evident; and in which multiple sources of evidence are used'. While, in Stake's (1995) terms, this is an intrinsic case study which seeks to understand a particular issue for its own sake, while practical action research is 'worksite' based (see Denscombe, 2010: 134) and while the relevance of the findings of that case study (see Mann, 2006: 78) are restricted to a particular context, there is good reason to believe that the constituent factors of that case can be found in a significant number of institutions and that the findings below can be used to inform responses to those factors. In this key respect, this is an illustrative case study which seeks to enable, among others, academics engaging in WP activities for the first time to understand some of the processes, points of tension and challenges within universities that are central to work in this area (see anecdotal value of case studies in Nath, 2005: 398-399). We use Lancaster University and our subject area, Politics/IR, approach as a means of illustrating the large number of possible approaches to maximise the value of WP programmes for academics. We regard the combination of practical action research and case study as offering some scope for critical action research, insofar as WP involves assisting in the transformation of people's lives and, by virtue of that, institutions. There are also implications for government and institutional policy with regard to promoting a WP agenda. These are discussed in the penultimate section.

\section{Forms of funding, the 'academic'/'professional' distinction and institutional pressures}

Actors within English universities have access to a range of funding sources for different WP activities. There are trans-institutional collaborations, such as the Higher Education Funding Council for England's National Networks for Collaborative Outreach (NNCO). Other networks have developed from this, such as the Cumbria \& Lancashire Network for Collaborative Outreach (2017), which is led by central university services, rather than academics, and provides information and teaching resources for WP activities within a specific region. There are also occasional external funds, such as that of the Research Councils UK (RCUK)-Schools Partnership (RCUK, 2016), which support specific, university-wide forms of collaboration led by academics. The most significant source, though, is that drawn from university OFFA 'allocations'. Universities have to abide by the National Strategy for Access and Student Success (HEFCE and OFFA, 2014), but liaise individually with OFFA to develop approved allocations from revenue derived from higher fees for use in WP procedures (OFFA, 2016c). This leads to a range of approaches 
within universities (McCaig, 2015). These funds are often distributed competitively through internal bidding processes. Perhaps the most readily available resources are those allocated to departments for subject-specific recruitment. Departments often liaise with central university services to demonstrate a commitment to ensuring that efforts are made within the remit of recruitment to recruit students from WP backgrounds. It is funding from this source which we will examine most closely on the basis that this will form the primary source of resources for academics engaging in WP.

Within at least some universities, particularly at the higher end of the university rankings, there are two broad, but not mutually exclusive, categories of actors engaging in WP work, though these may not clearly map on to traditional 'academic'/'non-academic' binaries. Whitchurch (2012: 99) is clear that earlier distinctions between academic and non-academic identities are dissolving as people in HE institutions increasingly 'work in multi-professional teams across a variety of constituencies' aimed at both understanding and responding to phenomena. Within such teams or forms of collaboration, 'professionals' may conduct research, while 'academics' participate administratively. WP programmes clearly involve some level of cross-over. However, there are many ways in which the distinction between the institutional 'core' and the academic 'periphery' remains (Clark, 1998) in terms of the motivations and pressures behind engagement in WP work. Perhaps a more accurate and less rigid distinction is articulated in Whitchurch's (2012) use of 'professional' and 'academic' participants.

'Professional' staff are those traditionally viewed as administrators or nonacademic actors working on particular projects not focused primarily on research. 'Academic' staff are researchers who engage in WP as part of their administrative work. There are professional staff engaged primarily with WP and institutionally located centrally in students' unions, recruitment offices or other sections devoted solely to outreach. Those at the heart of professional WP activity often lead non-subject-specific programmes, such as those associated with $\mathrm{NNCO}$, drawing in academics to provide subject-specific guidance. These professional programmes are grounded in the intrinsic value of WP. Professional staff engage with WP students with relatively little instrumental regard for attracting students to specific courses (see McCaig. 2016). As such, long-term programmes of engagement, such as those involving Villiers Park Educational Trust (2016) (a UK charity aimed at promoting educational success among disadvantaged teenagers), have been developed with students at General Certificate of Secondary Education (GCSE) level (13-16 years old) and younger, attempting to enhance general capabilities and challenge 'anti-intellectual' mindsets (see Baker, Brown and Fazey, 2006). These programmes are, potentially, of great value to society (see Miller and Smith, 2011; also critical account in Archer, 2007), especially at a time when social mobility is stunted. However, the nature of the 
profession means that leading such programmes is often unattractive to 'academic' participants in WP programmes.

Outside of disciplines like Educational Studies, academics generally engage with the WP agenda instrumentally through the administrative remit of undergraduate recruitment and admissions (see Rainford, 2017; Hoare and Johnston, 2011). This can take the form of organising ad hoc schools visits, on campus workshops and residentials as well as formal admissions processes. For academic departments, internal 'neoliberal' pressure to fill quotas and the financial incentive to increase student numbers are exacerbated in non-vocational subjects, such as Politics, which need increasingly to demonstrate the instrumental value of study (see Johnson, 2016; Mavelli, 2014). Academic-led programmes operate under the auspices of WP but are often grounded in subject-specific recruitment aimed at Advanced level (A level) students (16-18 year olds). There is evidence to suggest that, once committed to A levels, students have already bought into education as a means of professional and personal advancement (see discussion in Loveday, 2015). Given the need to demonstrate instrumental benefits in terms of subject-specific recruitment, academic programmes generally have less incentive to engage in intrinsic 'hard WP' work associated with younger, extremely disadvantaged cohorts, since the benefits of convincing young students to stay on for A levels are less immediately realised by particular departments. In effect, academic-led WP work at A level is often grounded in raising the performance of potential students to the level required for admission or in convincing high performing students to apply for a particular course at a particular university.

There is significant anecdotal evidence from colleagues at a range of distinct universities in Northern England that differences in intrinsic professional and instrumental academic engagement in WP programmes can lead to consternation for both parties. Some professionals regard an instrumental recruitment focus as perverting the nature of the endeavour. Conversely, some academics regard the non-instrumental approach with concern because it is felt that professionals fail to appreciate the pressure for subject-specific recruitment and the ways in which, for academics, administrative roles can detract from more career-enhancing research activities (see Sternberg, 2013). Conditions attached to funding, particularly funding associated with the OFFA allocation, mean that this conflict can be exacerbated by timeconsuming evaluation and reporting requirements that are managed by 'professionals' or academics in different departments. The consequence is that academics can be dissuaded from participating in such projects, depriving WP students of the essential academic contribution needed to enhance their capacity to reach HE (see Brown, 2012: 104; Harris and Ridealgh, 2016). Non-participation is unfortunate and we ought to recognise that much can be gained from effective collaboration between academics and non-academics. How, then, should academics navigate this field? 


\section{Inefficiencies: separate foci and a lack of regional engagement}

One important factor in academics' favour is that schools, particularly those with high numbers of WP students, need to engage with academics, rather than professionals alone, to provide their students with the subject-specific knowledge needed to progress to good universities. This means that academics have the bargaining power to develop funded programmes which meet their interests in demonstrating the value of a subject area and the value of a university in a comprehensive, cumulative and cogent form.

However, through examining existing programmes at our present institution, through discussions with colleagues at other institutions and through engaging with schools themselves, it appears that, too often, forms of academic engagement with schools are inefficient. Ad hoc subject area talks or guest lectures lack context and do not lead on to further, more productive engagement. They are disconnected from professional talks on $\mathrm{HE}$ or finance that are needed to demonstrate the feasibility of study (see their importance highlighted in Dodgson and Bolam, 2002: 2). They often neither deploy active learning techniques nor mimic university teaching environments, meaning that key opportunities are missed to spark interest or to enable students from disadvantaged backgrounds to reconcile their identities with academic success in a welcoming university setting (see Wilkins and Burke, 2015; Walker, 2008). Institutionally, such programmes are often uncoordinated both within and between departments, leading to multiple, potentially overwhelming, points of contact between university and school. Most importantly, such programmes seldom integrate outreach, WP and recruitment foci, meaning that schools can be suspicious of the motivations and value of activities, and much time and effort is wasted on separate endeavours. An integrated programme enables departments to access internally awarded/allocated WP funding for activities which do genuinely help schools and students, but which also have a direct, tangible, instrumental benefit for departments in terms of recruitment, both in terms of WP students and non-WP students who can attend the same sessions where there is no significant additional cost to the latter's participation.

The lack of integration is compounded by the failure to adopt to coherent regional strategies. As Brown (2012) has highlighted, WP has often been regarded as an attempt to draw students from the local, anti-intellectual, proletarian (or other) sphere into the cosmopolitan, intellectual, bourgeois, with universities focusing efforts on local areas in order to attract those unable culturally or financially to move away. Having already developed a local focus at Lancaster University, there emerged a university-level drive for nationwide programmes of WP and recruitment in order to increase scope and scale. Greenbank (2006b) and Thomas (2001) have shown that there are serious problems in assuming the uniformity of disadvantaged students and 
creating monolithic WP programmes. In part because of this intrinsic concern for the importance of WP programmes to appeal to particular people, as a subject area, we argued that it is not feasible, efficient or effective to develop a nationwide approach. Because of neoliberal market pressure to recruit and the finite nature of resources, 'academic' subject area programmes also have a particularly pressing instrumental need to engage with the particular, local concerns of particular disadvantaged students in particular geographical areas (see Green and White, 2007: ix). Instrumentally, such programmes can only gain real traction where awareness of the attractiveness of a course of study reaches a critical threshold. For academics, instrumental programmes, engaging systematically through culturally attuned programmes with several schools in a single area or among a particular group disproportionately underrepresented in HE, allows for cumulative benefit both through increased participation and engagement by teachers and increased awareness among students and parents, particularly where the programme is repeated annually and activities are publicised in the local press (which is easily arranged by press offices).

There are many different disadvantaged groups in different areas, meaning many different possible 'academic' programmes for the many different subject areas within universities. The important point is that programmes need to focus on the particular, rather than the general. To illustrate the considerations behind developing targeted regional foci, it is useful to outline the way in which we developed our programme for engagement in the North East of England (NE). We stress that this is merely an illustration and the answers we produced are not the answers for other subject areas or other departments at other universities. However, the considerations which led to our answers are, we argue, important for all academics seeking to develop programmes.

The first consideration was to identify a particular area with a substantial number of disadvantaged pupils with whom we could engage readily. For Politics/IR at Lancaster University, the NE seemed like a natural target, given its proximity and the relatively high number of WP students and schools (see Duke, Hassink, Powell and Puukka, 2006: 12-13). Although at present a lowrecruiting area, in the first three decades of the University's life, many students came from the region. However, engagement with alumni and A level teachers in the NE has suggested that a decline in regional engagement led to a diminution of awareness of the University, while two incidents of suicide during the last period of significant NE recruitment (the 1980s) left an erroneous impression of Lancaster University as a 'new' university with social problems. This view is at odds with Lancaster University's age (now over 50 years old) and position in the top ten universities, as well as its receipt of awards for accommodation (Lancaster University, 2016a). Through engagement with teachers and pupils known to the principal author of this article, we concluded that Lancaster University's location for NE students is 
intuitively appealing due to it being sufficiently far away (between 106 and 121 miles from Newcastle upon Tyne by car, depending on route) to generate in students a feeling of independence, while also being sufficiently close, both geographically, culturally and politically as part of the North (see Baker and Billinge, 2004; González, 2013) to engender some degree of comfort as a campus university near a small and easily accessible town. It is argued within our department, at least, that Lancaster University applicants in general are attracted to the comforts of a village-like campus life in a quiet area of the North. This enabled us to justify concentrating less on engagement with students used to living in the bustling metropolises of the South which had, previously, been regarded as a key, and previously inexplicably lowreturning, market for our department on account of population size.

Again, we emphasise the importance of recognising that applicants, as distinct individuals, are attracted by different constituent features of specific universities (Veloutsou, Lewis and Paton, 2004; Price, Matzdorf, Smith and Agahi, 2003). While Zirkel (2002) defends the academic benefit that raceand gender-matched role models provide to young people in the first 24 months of their university studies, there is a further reason to consider the importance of a shared regional background in contributing to the identification of role models. Having a programme leader from a NE WP background enabled target students to identify with the institution and regard it as part of their locale. Such a role model can demonstrate the opportunities available for students with a WP background in accessing and engaging with university in a meaningful and beneficial way, and so benefit the students even before attending university. The contours of a university mean that entirely different regional, as well as ethno-cultural, gender and sexual foci can be advanced, but it is important for academics to consider such factors very seriously when developing programmes. What, though, should a programme look like?

\section{Integrating endeavours into a single programme}

Whatever a programme's particular focus, it ought to: have context and relevance, so that students appreciate the political nature of the engagement and view the experience as part of their progress towards HE (Thomas et al., 2005: 152-154); achieve cumulative impact, so that each point of contact with students advances interest in the subject and capacity for successful application (Thomas et al., 2005: 168); introduce students to university-style teaching (Thomas et al., 2005: 164-5; Lowe and Cook, 2003: 75) and active learning experiences, such that they overcome misconceptions about HE (Hockings, Cooke and Bowl, 2007: 722 and 726-7) and reconcile their identity with university study (Read, Archer and Leathwood, 2003); and combine academic and professional elements, so that students are provided with the information needed to make an informed judgement about the 
professional and financial implications of study (Dodgson and Bolam, 2002: 24).

In our case, we developed a programme which focuses on facilitating five or, in some cases, six points of contact with Advanced Subsidiary level (A1/S level) students (16-17 year olds) at several regional 'hub' schools, which host events attended by other schools, as well as on campus. The students engaged generally take Social Science subjects, but some do not. The programme assumes no prior knowledge of the subject. With this in mind, we invested in three sets of resources: i) professionally designed and produced PowerPoint slides for academic subject area talks, which were developed from focus groups on student experience before, during and after undergraduate study and an audit of existing subject talks and marketing material; ii) a 'Radicalisation engagement' 'Research in a box' set of PowerPoint online teaching resources co-designed with our students and partner schools, which use footage taken from role play events to enable teachers to run minimodules as part of the 'Prevent' agenda (see Home Department, 2011) in A level classes; and iii) a 'Rethinking disadvantage' 'Research in a box' set of online resources for teachers to run mini-modules as part of their own WP activities.

Throughout the year, we have the following programme of engagement in schools:

In September, we contact schools to arrange visits and activities, identifying several 'hubs' capable of hosting events with visiting cohorts from neighbouring schools. We have found teachers appointed as Heads of Sixth Forms or Progression Tutors to be amenable to contact at this point. From October to January, we visit those schools which have expressed an interest in the programme, presenting introductory subject talks which outline the subject, introduce the programme and invite students to campus open and visit days which occur throughout the year. In November, we hold an Extended Project Qualification (EPQ) mentoring programme at a 'hub' school. This programme works in conjunction with a third year module, PPR389: Politics Employability and Engagement through Outreach (outlined in Johnson, 2016), in which our students provide mentoring to A level students from WP backgrounds on campus. This benefits both the mentors and the EPQ students, enhancing employability of the former and the HE prospects of the latter.

In the first quarter of the year, we then hold a number of day-long role play scenarios associated with the 'Radicalisation engagement' 'Research in a box' (Johnson, Mabon et al., 2016), in which students from several schools experience a university-style environment and act out the characters and roles of actors in political crises, such as those associated with ISIS. Role play scenarios facilitate dynamic forms of active learning (see Huerta, 2007), assist schools in meeting 'Prevent' requirements and provide students with 
additional experiences for their CVs and personal statements (see Johnson, REAP and Mutton, 2016b). Local press coverage facilitated by the Press Office has publicised the University effectively (see, for example, Hexham Courant, 2015). We then ask professional recruitment officers to visit schools, particularly during HE fairs and parents evenings, to give talks on finance and application processes. These visits occur as students are beginning to think about applying to university as they approach their A1/S level exams. From April to July, we publicise our annual 'New Political Minds' three-day residential workshop (see Lancaster University, 2016c). This is run by the Richardson Institute, the UK's oldest Peace and Conflict Research Centre, and is held in the final week of August as students prepare to return for their second year of A levels (A2). In this event, 50 AS level pupils (25 WP and 25 non-WP) work with Politics/IR staff and Richardson Institute Postgraduate Interns to produce a series of reports on the future of Britain as seen through the eyes of people as they gain the right to vote. The participation of current postgraduate students, of which $50 \%$ are always from WP backgrounds, as teaching interns fosters continuity in student culture and helps A level students to identify with the University and department. New Political Minds addresses a clear knowledge deficit on Politics/IR as a subject area. The event focuses on explaining the nature and breadth of the subject and discipline, in seminar and research settings illustrative of first year teaching, to students whose predicted grades meet entry requirements.

Although each event can stand on its own, the programme builds on the capacity instilled in each activity, such that, by the residential, students already have the capacity to think of themselves within a Politics/IR context and to consider Lancaster University a viable destination for study. As the programme focuses on A1/S level pupils (16/17 year olds), there is the full A2 level (17/18 year olds) year to gauge the impact of the programme and to support individual students through the application process. The 'Rethinking disadvantage' 'Research in a box' (Johnson, Mutton et al., 2016) complements this, demonstrating a broader, non-recruitment-based commitment to WP which enables schools themselves to run mini-modules produced by academics, but without further direct academic involvement. 


\section{Lessons: logistics, the importance of co- ordination}

In developing and running the programme, a number of considerations have become apparent.

First, from an instrumental perspective, the monetary value of students means that even relatively small increases in recruitment justify time and money invested. Although the numbers of WP students eventually applying to study Politics/IR at Lancaster University as a direct consequence of participation in the pilot version of the programme in 2014-2015 were small (five students), they still led to a $450 \%$ return on the $£ 10,000$ invested - around the salary cost of an academic member of staff. Once the pedagogical materials and relationships with schools are developed, the amount of time and money needed to sustain the programme declines, enhancing further any returns.

Second, schools, particularly those with high numbers of WP students, are under serious, increasing pressure to ensure exam success (Mortimore and Whitty, 2000). Such schools can adopt a self-defeating strategy with regard to certain cohorts, denying students leave to attend events in the misplaced belief that contact time in classes better prepares them for exams and progress to HE (see Brown, 2012: 104). This problem of perception can only be addressed through long-term engagement in order to demonstrate value. As the programme has developed, regional networks of teachers have facilitated shared understandings of activities. This is furthered by the introduction of the 'Research in a box' resources, which enable teachers to visualise events, such as role plays, which they may never previously have facilitated, leading to a higher response rate among prospective partners at the point of first contact.

Third, some less well functioning schools are unable to organise events, but can participate in other ways. By establishing several reliable 'hub' schools, such as Fuse Media Centre at Prudhoe Community High School, we have enabled less well functioning schools to participate without the burden of having to organise events on their premises.

Fourth, recognising the particular cultural context, practical conditions and important relationships within a target region enhances efficiency and effectiveness (Goddard and Chatterton, 1999: 696-697; Glasson, 2003). This requires specialist knowledge which can take time to amass and can sometimes only ever make sense to an insider (Geertz, 2000: 5). As the WP agenda and the need for subject-specific recruitment advances, the number of departments engaging in this sort of activity increases exponentially. Indeed, we were informed by one teacher that their school has been contacted separately by three departments in the same faculty at one university without any sign of co-ordination at all. A lot of this contact can be simplified by universities employing regional specialists capable of co-ordinating 
programmes across departments. This is emphasised by Vignoles and Murray (2016), who uphold the importance of co-ordination between departments, both internally within an institution and externally across institutions, but offer no empirical evidence that such co-ordination is taking place. This lack of empirical data regarding departmental co-ordination could be a result of the individualistic attitudes within university departments with regard to achieving targets (Pugh, Coates and Adnett, 2005). Such attitudes reduce the likelihood of institutional cohesion toward activities such as WP and recruitment. Therefore, this position need not be, and would benefit from not being, 'academic'. Indeed, there are generally 'professionals' with regional remits in recruitment offices, though, even there, the importance of local knowledge is often overlooked. However, a change in attitude would provide scope for academics to hold such roles within the UK Faculty system, coordinating subject-specific programmes within, for example, the Social Sciences, enabling local knowledge to be combined with general academic knowledge of the disciplines to facilitate effective contact between academics and schools.

Fifth, and perhaps most importantly, the different funding sources, combined with academic/professional differences in approaches, can lead to serious issues regarding the allocation of funds. Internal, university-wide bidding processes for Outreach/WP funding, such as that associated with the OFFA allocation, are generally presented as competitive across institutions. In contract, Faculty funding is often presented as grounded in need, with funds allocated to Departments that face particular recruitment challenges. That makes sense, given that WP is seen to be a challenge for individual universities as collective bodies. However, experience shared with colleagues across a range of universities indicates that instrumental, recruitment, needsbased considerations enter into processes presented as merit-based, with funds awarded to projects that promote recruitment within departments that are struggling to recruit. That poses a serious challenge for academics insofar as individuals may be devoting thought, effort and time to proposals that will be assessed according to criteria beyond their control. In general, greater clarity is required if individuals are to invest in bidding processes, even if the outcome is simply that proposals are advanced on the grounds of need and being able to demonstrate, through strong, established relationships with schools, means of satisfying that need. The problem for professionals is different. Given that the OFFA allocation is determined through agreement between OFFA and individual institutions, that professional positions are more likely to be located centrally in university services, and that professional positions are more likely to be held on fixed-term contracts, professionals have a practical, as well as intrinsic, interest in sustaining programmes that are run centrally, that are not subject-specific, that engage with a large number of WP students and that engage with academics on an ad hoc basis. The 
contrasting pressures faced by academics and professionals lead to potential points of conflict that cannot be resolved under the present neoliberal climate. For example, consider the implications of OFFA Funding being increasingly committed to employing WP professionals on ongoing contracts. This reduces the precariousness of their situation but, with no subject specialisation, means that academics have fewer avenues for leading such projects at a time in which there is greater pressure than ever for departments to recruit. While collaboration can, potentially, be of great benefit, it is clear that the structuring of arrangements and the distinct pressures create the basis for non-co-operation. This is important since the very existence of pressures that justify WP professionals, including the $£ 9,000+$ fees are threatened by a prospective shift in Government. What happens, to such professionals, if the very raison d'être of their roles is removed?

Sixth, quite aside from academic/professional distinctions in the aims of WP activity, the way in which the scale of WP engagement is evaluated by nonsubject specific bodies can be arbitrary. Often, it is students themselves who are asked to identify their WP status. For example, in one evaluation programme, students were presented with only some of the many WP criteria by which to categorise themselves as WP, such as whether they were disabled or a care leaver. Given the intermingling of categories and given the importance of understanding the challenges of particular groups, it is essential that disadvantage is identified effectively. In the NE, for example, it is possible that more reliable and relevant indicators of whether or not a student faces obstacles to participation are whether the student's household income falls below $£ 42,600$, because the increased tuition fees and cost of living mean that parents struggle financially to support children during study, and whether the student would be first in their family to reach HE, since HE represents a huge step culturally into the unknown (Read, Archer and Leathwood, 2003). The consequence of the evaluation form design was that some events in which it was likely, based on discussions with teachers that around $90 \%$ of students fulfilled at least one OFFA criteria returned WP rates of $20 \%$. Moreover, as students were asked to complete the forms themselves, there was a high level of spoiled responses, particularly from cohorts with high numbers of WP students from seriously disadvantaged backgrounds. The reasons for such forms of (self-)sabotage are enduring and include alienation and a desire to subvert power relations (see discussion in different contexts in McWhorter, 2000 and Bodkin-Andrews, Denson, and Bansel, 2013). In this instance, placing faith in evaluation methods which paid too little attention to local conditions were significant insofar as they created the potential for the programme to be regarded, erroneously, as engaging with too few WP students. It is essential, therefore, that academics engage closely with professionals to ensure that evaluation of programmes is accurate, since the outcomes of the evaluation can inform subsequent funding decisions. 
The final consideration is a political one. All of the problems discussed in this article stem from inequalities produced or exaggerated by neoliberal socioeconomic policy. As we stated in the introduction, forms of disadvantage are intermingled, compounding the obstacles individuals face in accessing forms of education which might facilitate mitigation of inequalities upon entry into the workplace. Attempts to widen participation are thoroughly hampered by the expansion of neoliberal market competition between and within universities. Subject areas are pitted against one another in the struggle to attract students, while academics are set against professionals as they seek strategies to maximise the potential for securing their positions. This article should, we hope, increase understanding of at least some of these pressures and the strategies which stem from them. However, awareness between academics and professionals of each other's pressures will not and cannot lead to the sort of harmony that would allow for more comprehensive, academically informed, programmes targeting 'hard WP' at earlier ages unless recruitment pressures are removed. These pressures stem, at least in part, from the periodic increase in tuition fees and the removal of student number caps in 2015-2016 (see Bolton, 2014), which allow 'leading' subject areas at 'leading' institutions to recruit heavily, placing increasing downward pressure on other subject areas and other institutions (see Fazackerley, 2017). At present, the zero-sum competition over ever increasing rewards means that academics, in particular, will have in terms of self-preservation to act ever more instrumentally. Moreover, there is the potential for the failure of departments to recruit to lead to institutional pressure which may lead professionals to start to see WP instrumentally through the lens of recruitment, leading to an exponential diminution of intrinsic strategies. As such, the sort of issues identified by this article can only be addressed, fundamentally, by Government removing market pressures and (re-)affirming the intrinsic value of learning. That seems a remote possibility at present.

\section{Conclusion}

We recognise that the specific approach outlined above seeks to engage centrally with people from a particular area and with a set of related backgrounds. This ought not to suggest that, as a department, we value these people more highly than those from other backgrounds or that we have an ethnocentric interest in the group. Rather, it reflects our belief that academics, given their various working constraints, need to focus their efforts carefully, engaging with those groups that can be reached most effectively. The nature of those groups will naturally differ from institution to institution. Unfortunately, the nature of the WP agenda, the distinction between academic and professional approaches and the conflict between merit- and need-based funding means that academic-led subject-specific programmes will always face forms of disruption and upheaval. However, by integrating agendas and adopting cumulative, regional approaches, time and effort can be saved and students attracted in numbers significant enough to warrant the initial 
investment. Creating programmes along the lines identified above can ensure that academic involvement in WP upholds research and recruitment interests and provides meaningful opportunities for WP students. Each programme ought to look different to reflect differences of institution and discipline, and it is essential that local knowledge is deployed to ensure that whatever approach is adopted makes sense to target groups. While this article has focused on the instrumental basis for developing WP programmes, it is important to note that attracting WP students to Politics/IR can radically enhance life chances as the principal author of this article, a former NE WP student, can testify. 


\section{References}

Archer, L. (2007) 'Diversity, Equality and Higher Education: A Critical Reflection on the Ab/uses of Equity Discourse within Widening Participation', Teaching in Higher Education, 12, 5-6: 635-653.

Baker, A. R. H. and Billinge, M. (2004) 'Material and Imagined Geographies of England' in Alan R. H. Baker and Mark Billinge (eds) Geographies of England: The North-South Divide, Material and Imagined, Cambridge: Cambridge University Press.

Baker, S., Brown, B. and Fazey, J. A. (2006) 'Individualization in the Widening Participation Debate', London Review of Education, 4, 2: 169-182.

Bodkin-Andrews, G. H., Denson, N. and Bansel, P. (2013) 'Teacher Racism, Academic Self-Concept, and Multiculturation: Investigating Adaptive and Maladaptive Relations with Academic Disengagement and Self-Sabotage for Indigenous and Non-Indigenous Australian Students', Australian Psychologist, 48, 3: 226-237.

Boliver, V. (2015) 'Are There Distinctive Clusters of Higher and Lower Status Universities in the UK?', Oxford Review of Education, 41, 5: 608-627.

Bolton, P. (2014) HE in England from 2012: Student numbers (Standard Note: SN/SG/6205), Westminster: House of Commons Library.

Brown, G. (2012) 'The Place of Aspiration in UK Widening Participation Policy: Moving Up or Moving Beyond?' in Peter Kraftl, John Horton and Faith Tucker (eds) Critical Geographies of Childhood and Youth: Contemporary Policy and Practice, Bristol: Policy Press, pp. 97-112.

Clark, B. (1998) Creating Entrepreneurial Universities: Organizational Pathways of Transformation, Paris: Elsevier.

Cumbria \& Lancashire Network for Collaborative Outreach (2017) 'Aims', Cumbria \& Lancashire Network for Collaborative Outreach. [Online]. Available at http://cumbrialancsoutreach.ac.uk/our-network/\#aims (accessed: 19 February 2017).

Denscombe, M. (2010) The Good Research Guide: For Small-Scale Social Research Projects, Maidenhead: Open University Press.

Department for Business, Innovation and Skills (2014) National Strategy for Access and Student Success in Higher Education, London: Department for Business, Innovation and Skills.

Dodgson, R., and Bolam, H. (2002) Student Retention, Support and Widening Participation in the North East of England, Sunderland: Universities for the North East. [Online]. Available at http://www.unis4ne.ac.uk/files/Retention report70.pdf (accessed: 27 July 2016).

Duke, C., Hassink, R., Powell, J., and Puukka, J. (2006) Supporting the Contribution of Higher Education Institutions to Regional Development, London: Organisation for Economic Co-operation and Development. 
Available at: https://www.oecd.org/unitedkingdom/35889695.pdf (accessed: 27 July 2016).

Edwards, A. and Talbot, R. (1994) The Hard-Pressed Researcher: A Research Handbook for the Caring Professions, London: Longman.

Fazackerley, A. (2017) 'What would happen if a UK university went bust?', The Guardian, 7 February. [Online]. Available at, https://www.theguardian.com/education/2017/feb/07/what-if-uk-universitygoes-bust-ucas-students?CMP=Share AndroidApp Fenix (accessed: 21 February 2017)

Geertz, C. (2000) The Interpretation of Cultures, London: Basic Books.

Glasson, J. (2003) 'The Widening Local and Regional Development Impacts of the Modern Universities - A Tale of Two Cities (and North-South Perspectives)', Local Economy, 18, 1: 21-37.

Goddard, J. B. and Chatterton, P. (1999) 'Regional Development Agencies and the Knowledge Economy: Harnessing the Potential of Universities', Environment and Planning \& Government and Policy, 17, 6: 685-699.

González, S. (2013) 'The North/South Divide in Italy and England: Discursive Construction of Regional Inequality', European Urban and Regional Studies, 18, 1: 62-76.

Graham, C. (2013) 'Discourses of Widening Participation in the Prospectus Documents and Websites of Six English Higher Education Institutions', British Journal of Sociology of Education, 34, 1: 76-93.

Green, A.E., and White, R.J. (2007) Attachment to Place, York: Joseph Rowntree Foundation.

Greenbank, P. (2006a) 'Institutional Admissions Policies in Higher Education: A Widening Participation Perspective', International Journal of Educational Management, 20, 4: 249-260.

Greenbank, P. (2006b) 'The Evolution of Government Policy on Widening Participation', Higher Education Quarterly, 60, 2: 141-166.

Greenbank, P. (2006c) 'Widening Participation in Higher Education: An Examination of the Factors Influencing Institutional Policy', Research in Post-Compulsory Education, 11, 2: 199-215.

Harris, P. and Ridealgh, K. (2016) 'Academic Involvement in Outreach: Best Practice Case Studies from Health and Languages', Widening Participation and Lifelong Learning, 18, 3: 74-83.

HEFCE and OFFA (2014) National Strategy for Access and Student Success, London: Higher Education Funding Council for England and the Office for Fair Access.

Hexham Courant (2015) 'Middle East in Spotlight', Hexham Courant, 1 May: 'News Section' 4. 
Hoare, A. and Johnston, R. (2011) 'Widening Participation through Admissions Policy - A British Case Study of School and University Performance', Studies in Higher Education, 36, 1: 21-41.

Hockings, C., Cooke, S., and Bowl, M. (2007) ““Academic Engagement” within a Widening Participation Context - A 3D Analysis', Teaching in Higher Education, 12, 5-6: 721-733.

Home Department (2011) Prevent Strategy, London: The Stationary Office. [Online]. Available at https://www.gov.uk/government/uploads/system/uploads/attachment_data/file 197976/prevent-strategy-review.pdf (accessed: 27 July 2016).

Huerta, J. C. (2007) 'Getting Active in the Large Lecture', Journal of Political Science Education, 3, 3: 237-249.

Johnson, M. (2016) 'Communicating Politics: Using Active Learning to Demonstrate the Value of the Discipline', British Journal of Educational Studies, 64, 3: 315-335.

Johnson, M., Mutton, R., Gallagher, V., Graham, M., Appleton, R. and Johnson, H. (2016) 'Rethinking Disadvantage: Research in a Box', Lancaster University [Online]. Available at https://openlearning.lancs.ac.uk/course/view.php?id=166 (accessed: 21 February 2017).

Johnson, M., Mabon, S., Helm, G., Gerger, L., Smith, T., Appleton, R. and Johnson, H. (2016) 'Radicalisation Engagement: Research in a Box', Lancaster University [Online]. Available at https://openlearning.lancs.ac.uk/course/view.php?id=165 (accessed: 21 February 2017).

Johnson, M., REAP and Mutton, R. (2016a) 'PPR 50 New Political Minds 2016', Lancaster University OFFA Evaluation [Online]. Available at https://openlearning.lancs.ac.uk/pluginfile.php/16561/mod_resource/content/1 /PPR\%20Summary\%20Report\%2050\%20New\%20Political\%20Minds\%2020 16.pdf (accessed: 21 February 2017).

Jones, N., and Lau, A. M. S. (2010) 'Blending Learning: Widening Participation in Higher Education', Innovations in Education and Teaching International, 47, 4: 405-416.

Lancaster University (2016a) 'Our Reputation', Lancaster University. [Online]. Available at http://www.lancaster.ac.uk/about-us/rankings-and-reputation/ (accessed: 27 July 2016).

Lancaster University (2016c) 'New Political Minds', Lancaster University. [Online]. Available at http://www.lancaster.ac.uk/ppr/news-andevents/forthcoming-events/5538 (accessed: 27 July 2016).

Lewis, B. (2002) 'Widening Participation in Higher Education: The HEFCE Perspective on Policy and Progress', Higher Education Policy, 14 : 361-376.

Loveday, V. (2015) 'Working-Class Participation, Middle-Class Aspiration? Value, Upward Mobility and Symbolic Indebtedness in Higher Education', The Sociological Review, 63, 3: 570-588. 
Lowe, H., and Cook, A. (2003) 'Mind the Gap: Are Students Prepared for Higher Education?', Journal of Further and Higher Education, 27, 1: 53-76.

MacLean, M. S. and Mohr, M. (1999) Teacher-Researchers at Work, Berkeley, CA: The National Writing Project.

Mann, B. L. (2006) 'Case study research and online learning: Types, typologies and thesis research' in Case Study Research on Web-Based Learning, London: Information Science Publishing, pp. 70-79.

Mavelli, L. (2014) 'Widening Participation, the Instrumentalization of Knowledge and the Reproduction of Inequality', Teaching in Higher Education, 19, 8: $860-869$.

McCaig, C. (2015) 'The Impact of the Changing English Higher Education Marketplace on Widening Participation and Fair Access: Evidence from a Discourse Analysis of Access Agreements', Widening Participation and Lifelong Learning, 17, 1: 5-22.

McCaig, C. (2016) 'The Retreat from Widening Participation? The National Scholarship Programme and New Access Agreements in English Higher Education', Studies in Higher Education, 41, 2: 215-230.

McGlinn Manfra, M. (2009) 'Action Research: Exploring the Theoretical Divide between Practical and Critical Approaches', Journal of Curriculum and Instruction, 3: 32-46.

McWhorter, J. H. (2000) Losing the Race, New York: The Free Press.

Miller, J., and Smith, C. (2011) 'Raising Aspirations and Widening Participation: An Evaluation of Aimhigher in Herefordshire and Worcestershire', Research in Post-Compulsory Education, 16, 2: 231-248.

Mortimore, P. and Whitty, G. (2000) 'Can school improvement overcome the effects of disadvantage?' in Theo Cox (ed.), Combating Educational Disadvantage: Meeting the Needs of Vulnerable Children, London: Falmer Press, pp. 156-176.

Nath, J. L. (2005) 'The Roles of Case Studies in the Educational Field', International Journal of Case Method Research \& Application, 17, 3: 396400.

OFFA (2016a) 'About OFFA', OFFA. [Online]. Available at https://www.offa.org.uk/about/ (accessed: 27 July 2016).

OFFA (2016b) 'Glossary', OFFA. [Online]. Available at https://www.offa.org.uk/glossary/\#W (accessed: 27 July 2016).

OFFA (2016c) 'Lancaster University Access Agreement', OFFA. [Online]. Available at https://www.offa.org.uk/agreements/University\%20of\%20Lancaster\%201617 .pdf (accessed: 27 July 2016).

Price, I., Matzdorf,F., Smith, L., and Agahi, H. (2003) 'The Impact of Facilities on Student Choice of University', Facilities, 21, 10: 212-222. 
Pugh, G., Coates, G. and Adnett, N. (2005) 'Performance Indicators and Widening Participation in UK Higher Education', Higher Education Quarterly, 59, 1: 19-39.

Rainford, J. (2017) 'Targeting of Widening Participation Measures by Elite Institutions: Widening Access or Simply Aiding Recruitment?', Perspectives: Policy and Practice in Higher Education, 21, 2-3: 45-50.

RCUK (2016) 'RCUK School-University Partnerships Initiative', RCUK. [Online]. Available at http://www.rcuk.ac.uk/pe/PartnershipsInitiative/ (accessed: 27 July 2016).

Read, B., Archer, L. and Leathwood, C. (2003) 'Challenging Cultures? Student Conceptions of "Belonging" and "Isolation" at a Post-1992 University', Studies in Higher Education 28, 3: 261-277.

Stake, R.E. (1995) The Art of Case Study Research: Perspective in Practice, London: Sage.

Sternberg, R. J. (2013) 'Self-Sabotage in the Academic Career', Chronicle of Higher Education, 59, 34: A36-A37.

Susman and Evered (1978) 'An Assessment of the Scientific Merits of Action Research', Administrative Science Quarterly, 23, 4: 582-603.

Thomas, L. (2001) 'Power, Assumptions and Prescriptions: A Critique of Widening Participation Policy-Making', Higher Education Policy, 14, 4: 361376.

Thomas, L., May, H., Harrop, H., Houston, M., Knox, H., Foong Lee, M., Osborne, M., Pudner, H. and Trotman, C. (2005) From the Margins to the Mainstream: Embedding Widening Participation in Higher Education, London: Universities UK. [Online]. Available at http://www.universitiesuk.ac.uk/policy-andanalysis/reports/Documents/2005/margins-to-the-mainstream.pdf (accessed: 17 January 2017).

Tight, M. (2012) 'Widening Participation: A Post-War Scorecard', British Journal of Educational Studies, 60, 3: 211-226.

Veloutsou, C., Lewis, J. W, and Paton, R. A. (2004) 'University Selection: Information Requirements and Importance', International Journal of Educational Management, 18, 3: 160-171.

Vignoles, A. and Murray, N. (2016) 'Editorial: Widening Participation in Higher Education', Education Sciences, 6, 2: 13.

Villiers Park (2016) 'About us', Villiers Park. [Online]. Available at http://www.villierspark.org.uk/about-us/mission-and-vision/ (accessed: 27 July 2016).

Walker, M. (2008) 'Widening Participation; Widening Capability', London Review of Education, 6, 3: 267-279.

Whitchurch, C. (2012) 'Expanding the Parameters of Academia', Higher Education, 64, 1: 99-117. 
Wilkins, A. and Burke, P. J. (2015) 'Widening Participation in Higher Education: The Role of Professional and Social Class Identities and Commitments', British Journal of Sociology of Education, 36, 3: 434-452.

Yin, R. K. (1984) Case Study Research: Design and Methods, Newbury Park, CA: Sage.

Zirkel, S. (2002) 'Is There A Place for Me? Role Models and Academic Identity among White Students and Students of Color', Teachers College Record, 104, 2: $357-376$. 